\title{
Customer value creation in value added telecommunication services
}

\author{
${ }^{a}$ Janne Takala, ${ }^{a}$ Olli Martikainen, ${ }^{b} J u k k a$ Ruusunen \\ ${ }^{a}$ Telecom Finland, P.O. Box 145, \\ FIN-00511 Helsinki, Finland \\ Tel. +358 20401, Fax +35820402320 \\ ${ }^{b}$ Systems Analysis Laboratory, Helsinki University of Technology, \\ FIN-02150 Espoo, Finland
}

\begin{abstract}
Advanced value-added telecommunication services provide high growth potential for telecommunication operators. Intelligent networks provide new opportunities for the development of differentiated value-added services. With increasing competition customer oriented service development becomes very important. In this paper we will present a framework for service development that includes both customer values and operations of the service provider. The framework of value network will be formed of customer preferences and the operations of the service provider. Our approach thus combines the theory of value creation in the company with consumer theory of how consumers perceive created values. We also give an example of the utilisation of the framework by analysing how customer value is created with the 9700-service of Telecom Finland.
\end{abstract}

\section{INTRODUCTION}

The demand for sophisticated telecommunication services and the rapid development of telecommunication techniques have created a basis for the development of Intelligent Networks (IN). IN support management and distribution of advanced telecommunication services. IN provides possibilities to integrate existing and new services, introduce new services rapidly, and differentiate services according to the needs of different customer segments. These new value-added services are created on top of existing telecommunications infrastructure and they utilise its services in value-added service applications. IN technology provides opportunities to offer value-added services to smaller and more profitable customer segments. 
The demand for advanced services will grow in the future. Currently only $25 \%$ of the revenue generated by telecommunication services is accounted for by advanced services. In the future the share will be higher, since the estimated growth rate of advanced services will be close to $20 \%$, as the estimated growth rate of basic services will be less than $5 \%$.[3]

The development of new value-added telecommunications services requires knowledge about markets, customer needs, and technological possibilities. With the knowledge it is possible to develop succesfully differentiated services that satisfy the needs of different customer segments and also provide profit for the service provider. Telecommunications service development has so far been technology oriented. As competition increases, customers' needs become more important and service development has to be customer oriented. The objective is to create low-cost services that provide high value to customers. The problem is how to develop the wanted services for the right customer segments so that they are profitable.

This paper will concentrate on the customer value creation of the value-added services. Our objective is to discuss customer values and how they are related to service differentiation in the modern telecommunications environment. We will formulate a framework that describes how customer value of a modern service is created in the value chain of a firm. The approach can be conceived as a part of a service portfolio analysis. We will use the concept of value networks instead of a value chain to describe the firm's value creating activities. The framework developed here can be used in service development, pricing, customer segmentation, and operations analysis.

In chapter 2 we will discuss customer values and service differentiation. In chapter 3 we will present a modern product concept that is subsequently used in chapter 4 where we will formulate a model for customer value creation of a value-added telecommunication service. In chapter 5 we will present an example of value-added services and its customer value creation. In chapter 6 we discuss further research possibilities and state our conclusions.

\section{CUSTOMER VALUES AND DIFFERENTIATION}

In this chapter we will first discuss definitions and meanings of customer value, since the concept does not have a unique definition. Secondly, we will discuss factors that influence how a customer perceives a service and what makes it valuable. Thirdly, we will address the issue of differentiation and its relation to the customer value.

\subsection{Customer values}

The concept of customer value is diverse. Its definition varies depending on the approach to the subject. Researchers, manufacturing managers, marketing executives and sales representatives understand it in different ways. Most definitions resemble each other in several ways but emphasize different aspects of the concept. In most definitions customer value is created in the customer's value chain by satisfying customer needs and wants, for example, in forms of increased efficiency, cost savings, increased revenue, pleasure, or image.

The concept of customer value is used in microeconomics, consumer behavior, marketing, and strategic management. Porter defines customer value as the amount buyers are willing to pay for what a firm provides them [10]. Moreover, he defines a concept of actual value or 
cumulative value that is the actual impact of the product on customer value. In microeconomic theory the concepts of total value and marginal value are used. A necessary condition for all the definitions of customer value is that the customer should perceive it. From the point of view of our analysis, we find two slightly different definitions useful.

The first definition of revealed customer value is defined as a sum of money the customer reveals (by buying or telling) to be willing to pay for the service. If the value is revealed by buying, the paid price is the revealed customer value, and it is assumed to be close to what customer is ready to pay. If the value is not measured by actions but by intentions or willingeness to pay asked in questionnaires, it is assumed that the customer does not distort his or her true preferences. The service may offer more value to customers than what they reveal, but due to competitive situation, uncertainties, or a desire to get a lower price, they can express a lower value. The definition is easy to conceptualize to customers. It is also meaningful to the firm, since the revealed customer value is what the firm would get from the service. The total value created in the firm is the total revenue. It is also important when trying to estimate the value of a new service that is not available yet.

The second definition of actual customer value is based on the actual value the service creates to the customer in the course of time of its utilisation. This definition is close to the total value concept of Glahe and Lee [4]. Porter defines this concept as actual value or the cumulative customer value of differentiation [10]. It is the upper limit for the price the service provider can charge from the customer, and in this way the upper limit for the revealed customer value. The actual customer value is a valuable asset to the firm if it is able to estimate it and communicate it to the customer, since it can provide an competitive advantage over competitors.

The estimation of the actual customer value is based on the understanding of the customer's value chain and its links to the service. The customer research methods and questionnaires may be used to estimate the actual customer value, but not all customer's are able to conceive the definition or estimate it. Often customers are not able to perceive all of the actual customer value even after they have utilised the service for a while. This often happens with services that are intangible and have high credence qualities [7]. This complicates the estimation process. The second definition provides a way to estimate to what extent customer's needs are satisfied or how much quality is offered.

It is important to understand the distinction between the two definitions. In service development it is important to maximize the actual customer value for two reasons. Firstly, a higher actual customer value facilitates charging of higher prices. Secondly, if the actual customer value increases more than the price, the probability of purchase increases since the customer will "get more value for the same money". The revealed customer value is important also for two reasons. Firstly, it is needed in price determination. Secondly, it is needed in profitability evaluations.

\subsection{Customer perceptions of services}

This service perceived by the service provider is a combination of features created in the service design, production, marketing and sales processes. The presence of all these features is intentional. The point of view is functional and operational and differs from customers' perceptions of the same service. 
Customers perceive the service in relation to their needs the service satisfies. The customer conceives the service as a bundle of various service attributes [7]. The attributes are closely related to the customer's needs the service satisfies. Some of these attributes are images of features, some are combinations of several features, and some are a creation of the customer's imagination and have no connection with the features.

Recent consumer models also classify the attributes according to their level of concreteness to the customer $[9,11]$. From the consumer's point of view a service value chain consists of service attributes, psychological and social consequences of using the service, and basic values to which the service consumption relates. However, in the following model we include only service attributes.

Examples of telecommunications service attributes are accesibility, communication, reliability, detailed billing, value-added services, mobility, price, status, convinience, capacity, consistency, quality, and information security. The market can be segmented also according to the attributes that are demanded by different customer groups. Customer research methods utilise attribute evaluations in questionnaires [6]. The obtained data can be used in the service development process.

\subsection{Service differentiation}

The value-added services created with IN are essentially differentiated services, ie. they have some features that are not prevalent in the basic services. Differentiation is one of the three types of generic strategy to gain competitive advantage, and one of the two basic types of competitive advantage [10]. In service industries differentiation is an alternative solution to price competition.

The idea of differentiation is to provide something unique and different that has value to the customer, ie. to satisfy customers' needs in a new way better than competitors. Differentiation allows the firm to charge a premium price from its customers, to sell more of its service, or to gain intangible benefits like increased buyer loyalty [10]. The ideal situation would be when differentiation helps the firm to increase both the margin and the volume of sales while satisfying customers. A service can be differentiated by adding a unique feature to the set of existing service features. Another way to differentiate is to create the existing service features in a new and unique way.

Service differentiation is therefore succesful if the firm can offer something that satisfies the needs and wants of the customer that have not been satisfied yet. The objective is to provide quality solutions and in this way maximize the actual customer value. If the firm is able to communicate the increase in actual customer value, it can increase the sales volume, charge a premium price and keep customers satisfied.

Service differentiation is not an easy strategy for the firm. Customer needs may have been interpreted in a wrong way and the service fails to generate any sales. The service development may be too costly and the service is never profitable. The initial price may be too high and the predicted demand never actualizes. Even if the above mentioned pitfalls are avoided, competitors may soon imitate the service thus eroding the competitive advantage. In the long run the differentiated features may lose their importance to customers and become more generic.

The keyword to the issue is customer orientation: focusing on customer needs and wants, differentiating the service according to them and providing quality solutions. Customer 
orientation will be an important source for competitive advantage in telecommunications business in the future. Service providers will use this approach especially with business clients who are a major customer group for value-added telecommunications services.

With IN technology it can be possible to create differentiated value-added services costeffectively, but several questions remain. How to create cost-effectively services that satisfy customer needs and create actual customer value? What is the correct price level considering the revealed customer value and competitors' pricing? The problem is how to identify different consumer needs, how to express the identified customer needs in monetary terms as customer value, and how the value is cost-effectively created in the firm's value chain.

Our objective is to create a framework that would help to identify how customer value of a differentiated value-added service is created in different parts of the value chain, i.e. to explain how resources and technological aspects are transformed to tangible and intangible attributes that are conceivable to customers in monetary terms. The subject is approached from the point of view that is applicable to a telecommunications environment.

In order to do that, we must define such concepts that can be used in value chain analysis and in customer research. Therefore, we must define the value chain of a company so that it is more applicable to the modern telecommunications environment. We also have to determine the connection between the attributes that are familiar to customers and the features created in the value chain. We will use a modern product concept that helps to approach the problem. With the product concept it is also practical to define production platforms that are used to produce and create the different elements of a modern service. The concepts are defined in the next chapter. Using these concepts we will formulate a model of customer value creation.

\section{A MODERN PRODUCT ${ }^{1}$ CONCEPT AND PLATFORMS}

Lahti and Martikainen [8] define modern products as combinations of product elements provided by the firm. These product elements are defined as the presentations of the basic and

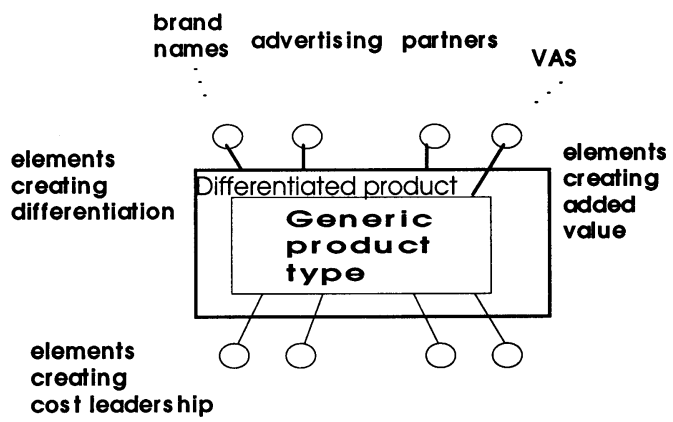

Figure 1. Elements of a product.

support activities of the firm in the products. Different products are different combinations of

\footnotetext{
${ }^{1}$ The product concepts and definitions apply also to services.
} 
these elements. Some of these elements create cost leadership, value adding and differentiation characteristics of the product. One element can therefore create more than one of these characteristics. The elements, which are the same as product features, provide competences for the product. Hereafter when we discuss features we refer to product elements. In the definition of the modern product concept we emphasize the difference between the generic and the differentiated product. This is presented in figure 1.

Examples of telecommunications product features are access, transmission, switching, billing, database, maintenance \& network supervision, administration, mobility, intelligent switching, and value-added service features. The features can be created by different companies. Companies can be telecommunication operators, telecommunication service providers, 3rd party service providers, or even customers.

The way these features are combined in the value chain is defined in product development. Basic questions are what features should be included in the products and in what extent, how these features are produced in the value chain, and how customer value is distributed among the features. If the cumulative cost of producing these features is higher than their cumulative value in the long run, it is difficult to justify the inclusion of the features in the product.

Lahti and Martikainen define the combination of synergic product features as platforms. Platforms can be regarded as a resource base that is dedicated to produce these synergic product features. The product features are created in the platforms. Platforms are determined based on the feature synergies. The synergies between the features are based on economies of scale and scope. Logistics, resource, and marketing synergies can also exist between two or more platforms. We can identify for example production platforms, channel platforms, and advertising platforms. The definition of platforms generally as a synergic concept leaves flexibility to the framework presentation.

Examples of telecommunication platforms are R\&D, access network, local trunk network, trunk (national) network, IN, advertising, sales, customer service, accounting and invoicing, and administration. Telecom Finland uses the platform concept in its business analysis.

In order to present the framework focusing on the features, attributes, and synergies existing in the process we need a description of the firm's value activities that is different from the value chain concept as defined by Porter [10]. Instead we will use a value network concept that is defined in the next chapter. We use the concept to model a customer value network consisting of attributes and a service provider value network consisting of features and platforms. In these value networks it is possible to analyse the nature and extent of synergies inside the firm, between the attributes, and in the total framework.

\section{CUSTOMER VALUE CREATION}

In this chapter we discuss first the customer value network which consists of service attributes important to the customer and relations between them. Secondly, we analyse in the same approach the value network of platforms and features, and the cost accumulation in the value network. Thirdly, we present a connection between the networks to form the customer value framework. Fourthly, we discuss possibilities to proceed to analyse the customer values using the framework as a conceptual basis. 


\subsection{Attribute network}

As described in section 2.2 the customer perceives the service as a set of attributes. These attributes include usually several product features. The customer is able to estimate the strength of preference based on the number and quality of potential features in the attribute. The attributes are also affected by other factors that are not features, like subjective beliefs about product performance. The overall value of an attribute is related to the needs it satisfies.

The attributes present in the service create the customer value. Each attribute has some value to the customer depending on the level of satisfaction it provides. A part of this value is independent of the other attributes in the service, and a part of the value depends on the value of the other attributes. The value that is dependent on the value of other attributes is synergic value. The attributes and their values form a customer value network that describes the overall customer value of the service and the synergic values of the attributes. The customer value network is described in figure 2 .

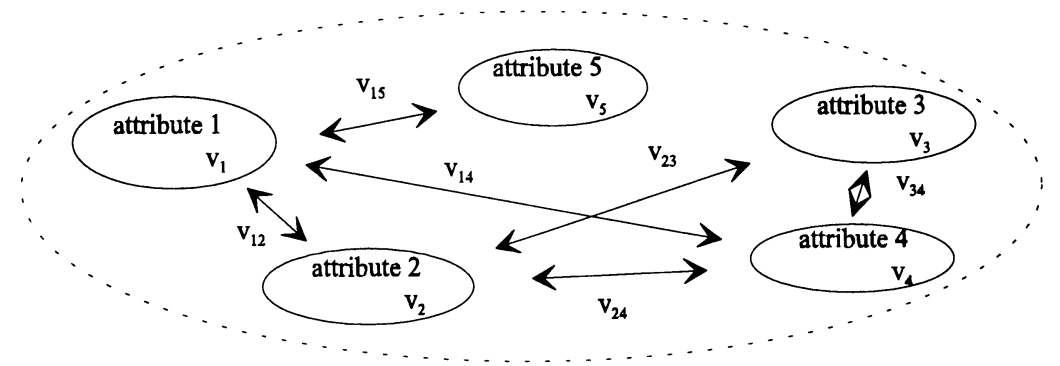

Figure 2. The customer value network.

The customer value network can be thought of as a part of a larger system, an attribute space $\mathcal{A}$. The attribute space $\mathcal{A}$ is set of all the possible attributes conceivable to customers. The services are synergic combinations of the attributes in $\mathcal{A}$. These combinations and their synergies can be described as value networks.

The customer value of the service that is formed in the attribute network can be described mathematically as a value function (see [12]). The value function includes as variables the attributes present in the service, all the features included in attributes and some other factors relevant to the decision making. The general form of the value function of the $i$ th service in the service portfolio ( $N$ services) is

$$
V_{i}=f\left(X_{i j}\left(y_{j k}, e_{j l}\right)\right), \quad i=1 \ldots N, j=1 \ldots M, k=1 \ldots P, l=1 \ldots R .
$$

$X_{i j}$ is the $j$ th attribute in the $i$ th service, $y_{j k}$ is the $k$ th feature in the $j$ th attribute, and $e_{i l}$ is the $l$ th non-feature element in the $i$ th attribute.

Depending on the nature of interdependence between the attributes it is possible to derive a mathematical form for the value function. Examples are additive and multiplicative multiattribute value functions. A necessary condition for multiplicative value function is mutual preferential independence between all the attributes. For an additive value function a stronger 
necessary condition of additivity independence is required [2,12]. An example of a multiplicative attribute model is presented in [6]. Additive functions do not include interdependencies between attributes, but since they are less complex than multiplicative models, they have been used much in empirical consumer research [11].

Previously customer research methods have been developed to predict customer preferences based on their beliefs of attributes and, in some models, also weights given to them [11]. Questionnaires provide possibilities to obtain information of customer preferences between products, services, attributes, and features. New and differentiated services, attributes, and features are compared with existing and more generic counterparts or with an "ideal service". The methods provide results that are measured both with qualitative measures and also on some quantitative scale like in monetary terms. However, the network approach in which also the interdependencies of different service attributes are studied, has not been very common so far.

Telecom Finland has studied customer preferences and evaluations of several of its services. Research has been performed also on the services utilising IN. The customer research of 9700service will be used in the example in chapter 5 . In the future the increase of competition in the telecommunication markets will increase the importance of customer research in general.

Based on empirical customer research such methods as conjoint analysis and multidimensional analysis have been used to get quantitative results about customer values [5,12]. Another similar method that provides qualitative results about customer requirements is Quality Function Deployment (QFD) process (Akao [1]). These methods are useful in customer segmentation, service development and pricing decisions.

\subsection{Feature network}

The features and platforms form a service provider's value network where the customer value is created in the service creation processes. The feature network describes actually the cost accumulation of the service creation process. There are costs incurred by the creation of each of these features and costs of combining the features to the service.

Platforms, which are synergic concepts and combinations of synergic service features, describe the basic and the support functions of the firm. They form a value network that describes the nature and extent of synergies in the firm. The value network composed of features describes the value creation of one particular service. The platform network creates all the features that are included in the services of a certain service portfolio. Since the features are elements of platforms, these networks are actually one value network that describes the cost accumulation and synergies in the firm. These synergies are results from economies of scale and scope in the platforms, and logistics, marketing, and resource synergies between the platforms.

We can describe the value network of features and platforms as a feature space $\mathcal{F}$. The feature space $\mathcal{F}$ is a set of all the features that the firm is able to create. The services are a union of the elements (features) present in the service. The platforms are unions of synergic features, and therefore subspaces of the feature space. The value network can be described as relations between the platforms when we are studying the service portfolio and as relations between some features when we are studying a single service.

Figure 3 illustrates the feature space $\mathcal{F}$. The solid black circles and ellipsoids describe the features. The platforms are described with ellipsoids drawn with dotted lines. The feature 
space is bounded by the large ellipsoid. For example, the grey circles are the transmission and switching features created in trunk, local, and access network platforms.

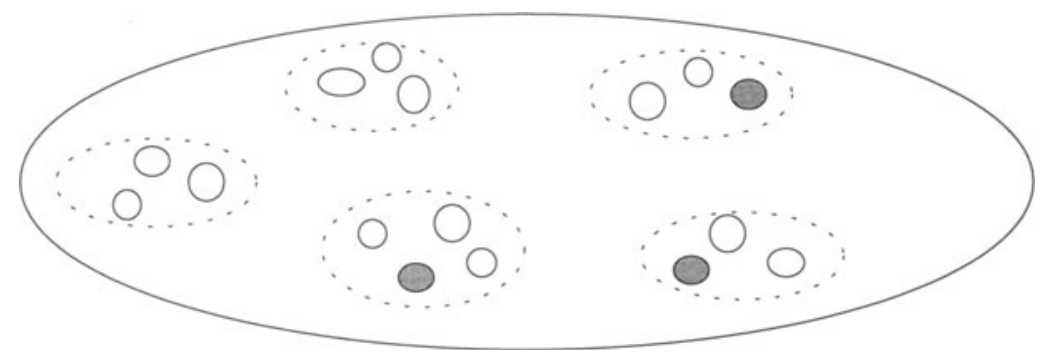

Figure 3. The feature space $\mathcal{F}$ and platforms.

In telecommunications industry the cost structure of platforms is different from, for example, the process industry. The platform can be described as a common resource for these services. In many platforms the majority of costs are not variable but fixed, and in most cases they are not direct but indirect costs. The features of one platform are included in several services, so the costs of the platform should be allocated to the services according to the amounts these features are used by each service. In consequence, changes in the volumes of one service affect the cost structure of all the services. The cost allocation is problematic, but using principles of activity based costing it is possible to allocate the costs in a way that describes the actual cost accumulation.

Telecom Finland has developed a cash flow model for the analysis of the value network. The model includes the services and the platforms of Telecom Finland, costs, investments, and revenues on a yearly basis for five years. The cash flow model can be used for many purposes: in intertemporal strategic analysis, service portfolio analysis, and scenario calculations.

\subsection{The connection between the networks}

The connection between the feature space and the service attribute space is a mapping $\mathcal{M}$ that interconnects the customer value of the service to the features included in the service, and maps the cost accumulation of features to the attributes. The mapping is described in figure 4.

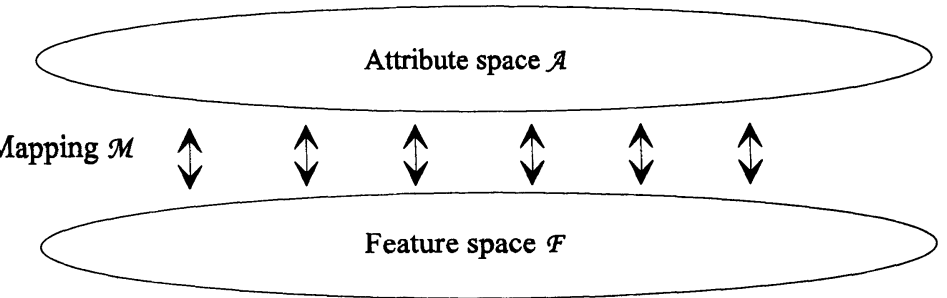

Figure 4. Mapping $\mathcal{M}$ between the feature space and the attribute space. 
The mapping $\mathcal{M}$ should be able to describe the synergies between the attribute space and the feature space as well as the synergies between each attribute and feature. Such a mapping would be highly nonlinear and currently we cannot present any explicit way to present it. In general we have a triple that consists of the attribute space $\mathcal{A}$, the feature space $\mathcal{F}$, and the mapping between the spaces. The mapping $\mathcal{M}$ interconnects the customer values of all the services to the features and also costs of all the features to all the attributes. In this way it is possible to analyse what features and attributes are profitable to provide.

The mapping $\mathcal{M}$ defines how the customer value network and the service provider value network are connected. It describes how the information from one network is transferred to the other network. An example is the connection between a customer value function and the cash flow model of Telecom Finland that is illustrated in figure 5.

\begin{tabular}{|c|l|}
\hline $\mathcal{A}$ & $\begin{array}{l}\text { A mathematical model of the customer value network } \\
\text { An example: a multiplicative value function } \\
\text { Data from customer research } \\
\text { The scope of the analysis: one service, current situation }\end{array}$ \\
$\mathcal{M} \quad \begin{array}{l}\text { attributes } \\
\text { prices } \\
\text { volumes } \\
\text { customer segments }\end{array}$ & $\begin{array}{l}\text { features } \\
\text { costs } \\
\text { investments } \\
\text { profitability }\end{array}$ \\
\hline $\mathcal{F}$ & $\begin{array}{l}\text { A mathematical model of the service provider value network } \\
\text { An example: the cash flow model of Telecom Finland } \\
\text { Data from customer research and internal sources } \\
\text { The scope of the analysis: all the services, several years }\end{array}$ \\
\hline
\end{tabular}

Figure 5. The connection of value models.

With some restrictive assumptions it is possible to derive a mathematical form for the triple. Such assumptions include that, for example, not too many features and attributes are present in the service, and mutual preferential independence exists between the attributes. In chapter 5 we present an example of value formation in Telemedia services.

\subsection{Using the framework}

Since the exact form of the general model is difficult to derive some other methods can be utilised to get service development information. It is possible to utilise customer research methods to get results for a service that is differentiated by adding only one or two new attributes. In such a case it is possible to compare the old, more generic service with the new, differentiated service and deduct the value of the additional differentiated attributes. Such questionnaires are quite possible to formulate using the customer research experience (see section 4.2). Using these methods it is possible to identify segments on the market, estimate the potential sales volumes in each segment, and to predict the suitable price level in each customer segment. 


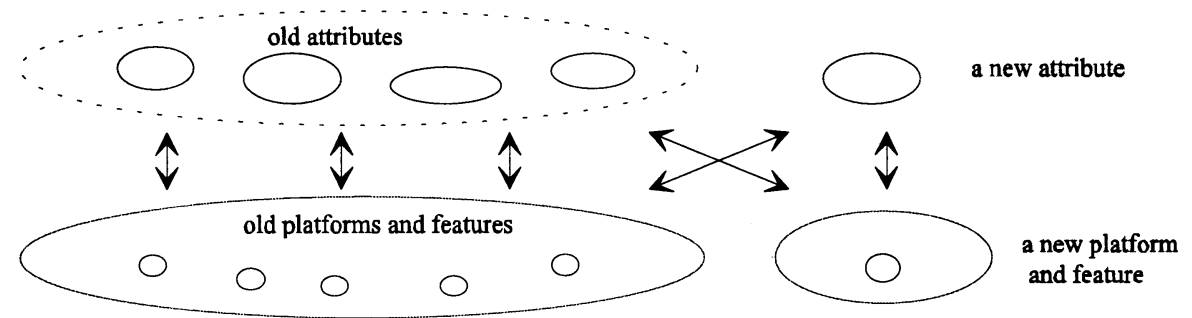

Figure 6. Customer value and cost evalution description of a new service.

With the same logic it is possible to calculate the cost accumulation in the firm with the old service portfolio and sales volumes. Using the customer research data it is possible to estimate product development costs, marketing costs of the new services, and the overall cost structure of the firm with the new services and the new sales volumes. After this it is possible to calculate scenarios for different market situations and estimate which service versions are profitable in which market segments.

Similar methods have been used in service and service development processes for a long time. What is new in our approach that it includes customer values (and higher degree of customer orientation), a systematic approach in which the value hierarchy from customer value attributes is matched with the value network of the company. It is an approach which also models the synergies between the elements in the hierarchy.

There are, however, many questions to be answered. The first is: Is it possible to get concrete results that are applicable in business operations? This has already been proved to some extent by some examples with a not-so-comprehensive approach to the subject [6]. Using customer research methods it is possible to estimate the strengths of preferences for the different attributes and whether the necessary conditions of additive or multiplicative functions hold. With the help of thorough insight to the firm's operations and activity based costing it is possible to model the feature and platform networks. Using expert estimates and research data it will be possible to determine the mapping, first with strong assumptions, and in the course of time with increasing insight, with weaker assumptions. The framework is therefore identifiable.

The second question is: Is it worth the trouble? Somewhat similar results can be obtained with ad hoc methods. The difference is that the theoretical basis increases the applicability of the results. Moreover, the process of studying value hierarchy can result in invaluable insights into the business. The analytical results can provide new information not only for service development and market segmentation, but also for inceasing the efficiency of existing platforms. A significant benefit is also that the clear concepts of the systematic approach facilitate communication in the organization. Misunderstandings can be avoided and common goals become evident to everybody.

\section{EXAMPLE: TELEMEDIA-SERVICES}

In this chapter we present an example of structuring the value hierarchy. The objective is to describe the logic of the framework and not so much to derive analytical results. The object of the example is a service in Telemedia service portfolio of the case firm Telecom Finland. 
Telemedia services are a group of modern telecommunication services based on sophisticated technology to provide customer oriented applications. The major service groups in Telemedia include EDI and telematic services, intelligent telephony service, and video and telephone conferencing. The Telemedia services include 9700-Telemarket, 9800-Free Phone, electric mail, Telecard-services and voice center services. The core idea of the Telemedia service group is to provide services related to intelligent information transmission and delivery.

Instead of using all these services we focus on 9700-Telemarket services. There are several reasons for this. Firstly, the 9700 -service generates a major part of the revenue of Telemedia. Secondly, the Telemedia services have different features so it would be difficult to analyse all of them together. Also the basic idea of our approach is to analyse customer values of a single service from a larger service portfolio. Thirdly, customer segments differ from one service to another, which means that service attributes vary much. This would also complicate our analysis.

The 9700-Telemarket service is similar to 900-numbers in the USA. Telecom Finland, the telecommunications operator, sells these services to companies. These companies, 3 rd party service providers, create the information or the actual service and market the service to end users. The end users vary much from consumers to business customers. Telecom Finland provides the intelligent infrastructure on which the 3rd party service providers can create services that customers demand. Telecom Finland charges the end users in phone bills, deducts its own revenue and forwards the money to the 3rd party service providers. Telecom Finland also provides reports and consulting services to the service providers.

\subsection{3rd party service providers as customers}

We first analyse the service excluding the end users and focusing on the 3rd party service providers as customers. The inclusion of the end users in the analysis would be most

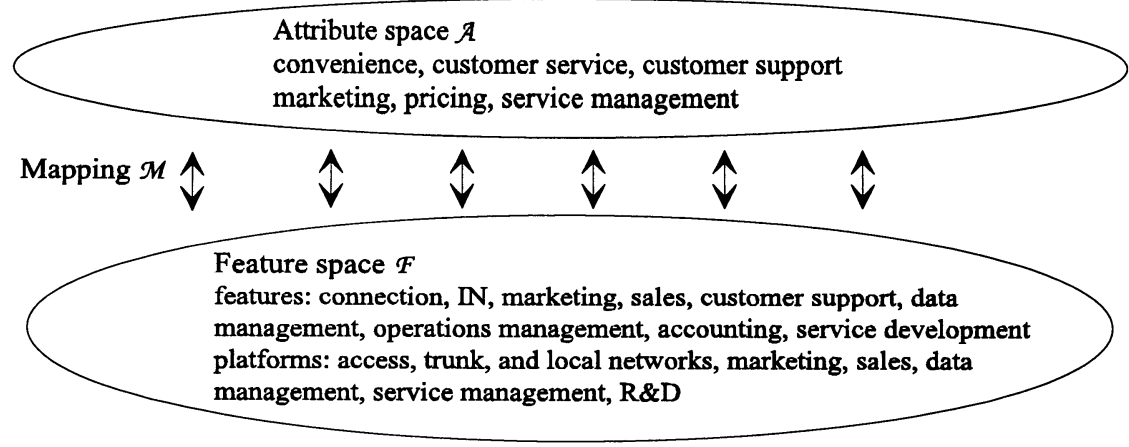

Figure 7. A model of 9700 -service with 3rd party service providers as customers.

interesting but currently we do not have empirical data for that purpose. We will discuss this aspect in chapter 5.2. As for the customer value attributes, they are defined from the point of view of the 3rd party service providers. These companies have also graded the performance of Telecom Finland on each attribute and estimated the weights of the attributes. The features of 
the 9700 -service have been defined by Telecom Finland. Activity based costing methods have been used to calculate the cost structure of platforms and features. The value hierarchy is presented in figure 7.

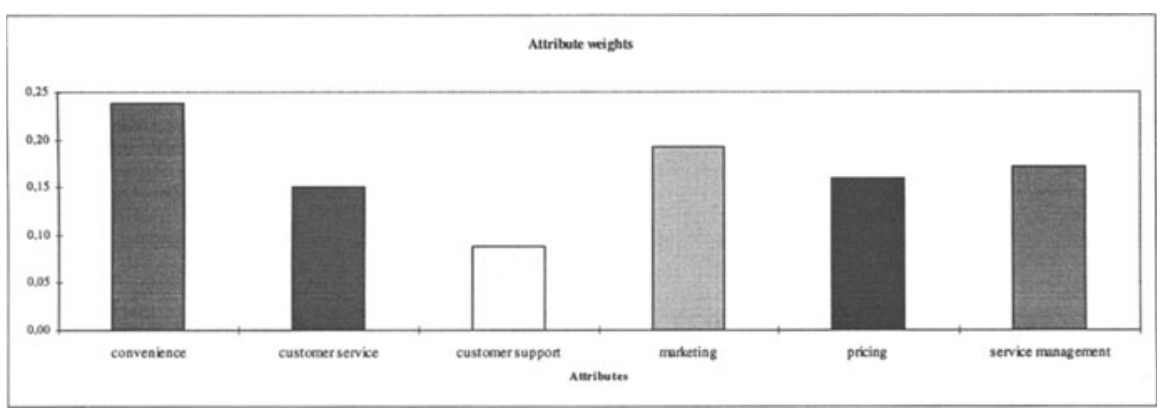

Figure 8. Attribute weights.

In customer value calculations we use the definition of revealed customer value, since we use the revenue as a measure of customer value. We make an assumption that the mutual preferential independence exists between all the attributes. Moreover, we also make a strong assumption of additivity independence between the elements. The available research data does not support these very strong assumptions, but since our objective is to provide an example of the logic of value creation, we keep the example simple.

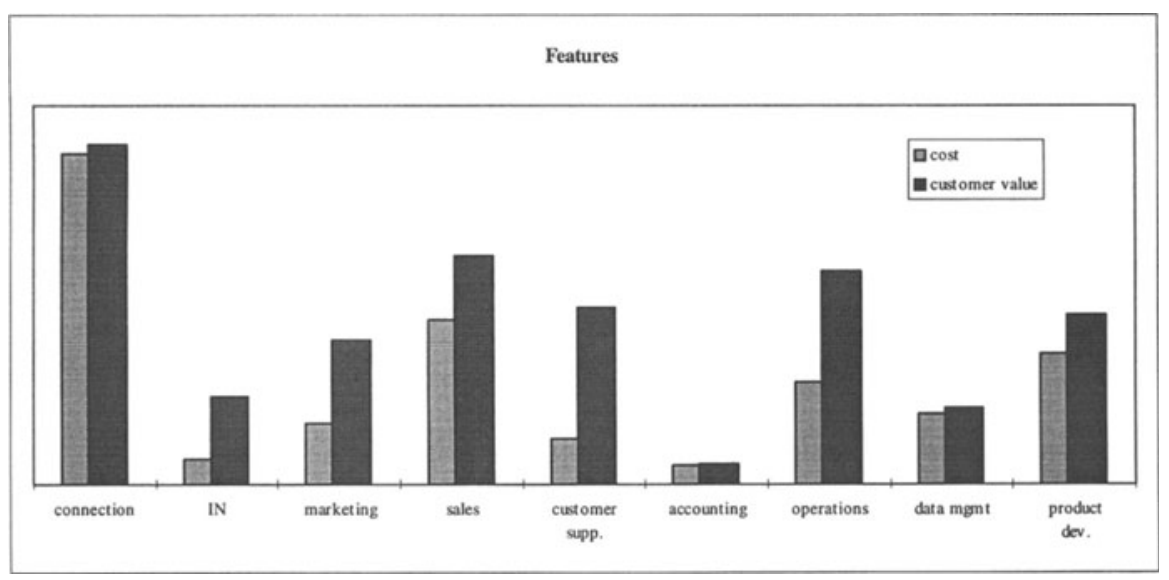

Figure 9. Feature cost and customer value structure.

The attribute weights are given in figure 8 . They have been calculated using customer research data and based on the above mentioned assumptions. In the calculations both the 
relative importance of the attribute and the customer satisfaction in the attribute have been considered.

Using the attribute weights and estimated relations between the attributes and the features we have calculated the value structures of the features and the platforms. We assume that each feature is necessary in the service from the operational point of view, and due to this the customer values of the features exceed their costs. The cost and customer value structures of features and platforms are given in figures 9 and 10.

The service feature IN is in this case the intelligent switching and it is "created" in the service management platform. The customer support feature is the after-sales service that handles application support. The operations feature manages the actual service creation excluding the IN. The customer service platform in figure 10 is responsible for customer support and accounting. The service management is responsible for operations and IN.

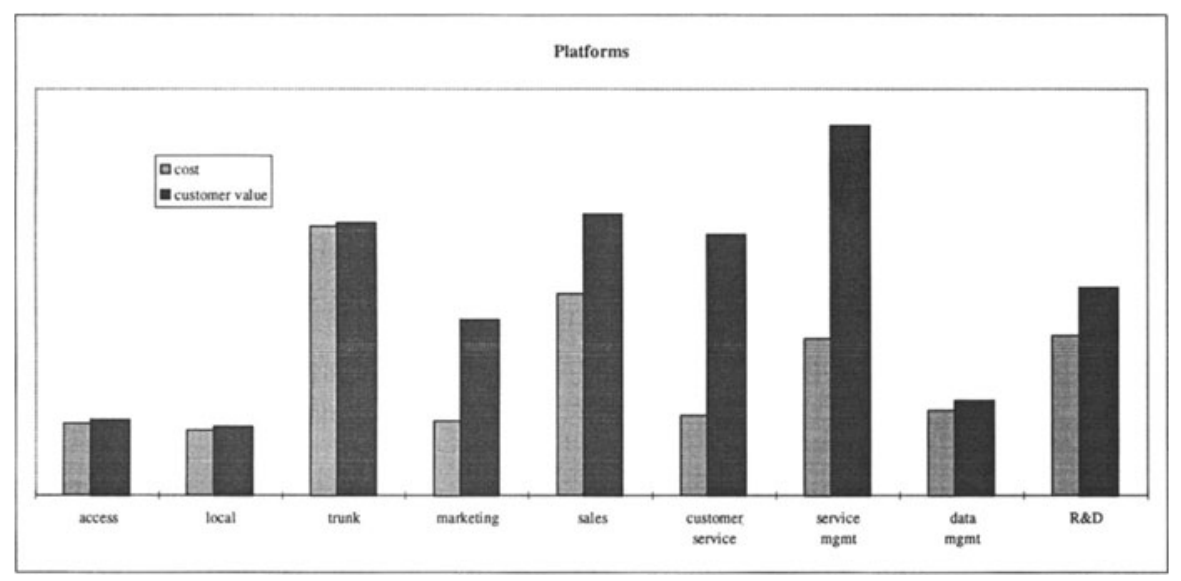

Figure 10. Platform cost and customer value structure.

The results provide information about customer attitudes and possible efficiency improvement targets. Although the results are just descriptive ${ }^{2}$, the small difference between customer value and costs in the network platforms and the higher importance of more customer oriented features is not unexpectable.

\subsection{3rd party service providers as platforms}

A more comprehensive approach to the service concept includes the 3rd party service providers as platforms in the total value network, which includes infrastucture and end users. The approach is important because it includes the real source of customer value, namely the end users. Their needs and attributes should be considered in the service development. The customer value in the new approach is the amount paid by the end user.

\footnotetext{
${ }^{2}$ Original cost and revenue figures have been altered because of business secrecy.
} 
In our framework a more comprehensive view including end users brings more information about the value network and the distribution of value among features, platforms, and service providers. The distribution of value between telecommunications operators and 3rd party service providers will be an important issue in the future, when the number of 3rd party service providers increases.

The more comprehensive approach would change the system of our 9700-service example. The 3rd party service provider's operations are included as additional features and platforms as described in figure 11 .

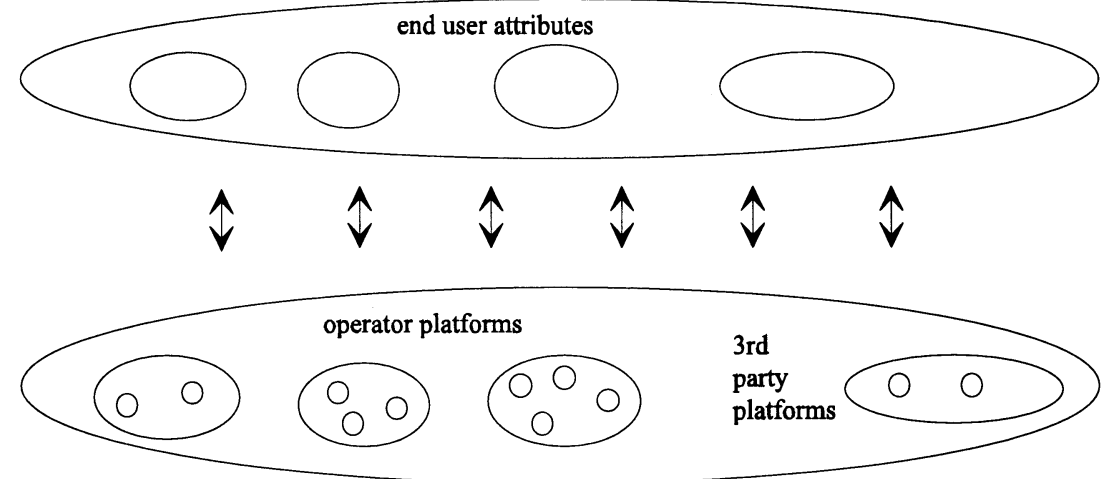

Figure 11. A model of 9700 -service with 3rd party service providers as platforms.

A comparison of the results of the two approaches would provide interesting results about the pricing of the services. Necessarily the customer value would not be divided "correctly" between the 3rd party service provider and the telecommunications operator. Possible reasons for this are the competitive situation determining the price levels or the telecommunications industry structure in general. The results would also be interesting considering cooperation opportunities between the companies. Information could be obtained about efficiency improvement, cooperation, and task division possibilities. Currently there is no research data available for this kind of analysis.

\section{DISCUSSION AND CONCLUSIONS}

The growth of the demand for advanced telecommunications services provides opportunities for IN-based differentiated value-added services. As the competition increases in the telecommunications industry the customer oriented service development provides possibilities for competitive advantage. Therefore, a systematic approach to analyse customer needs and values in the service development process is important, because it clarifies concepts and changes the emphasis in service differentiation from technology to customers. In this paper we have formulated the framework that serves these objectives.

The framework connects customer needs and values with the value activities of the service provider. Definitions and meanings of customer value are discussed in the context of service differentiation. We analysed customer preferences and the service provider's operations using 
the concept of value network. What is new in our approach is that the framework developed in this paper connects the customer value network and the service provider value network. The framework also provides new possibilities to analyse interdependencies between the service attributes and features.

In the paper we described the methods to perform customer value analyses. Telecom Finland has undertaken several customer research projects which have provided valuable information about customer preferences and the customer value network. The cash flow model developed in Telecom Finland is used in analysing the value network of the company. The cash flow model is useful in intertemporal strategic analysis, service portfolio analysis, and scenario calculations. The company value network is easier to analyse than the customer value network since more information is available, the subject is less ambiguous, and methods have been developed for a longer time.

We presented an example of the customer value creation in 9700-Telemarket service. The service utilises the IN-platform of Telecom Finland in its service creation. The example describes the logic of customer value hierarchy. Customer value structures of the service features and platforms were presented.

The framework can be used with several related research subjects. The efficiencies and synergies in platforms can be analysed with the model. The scope of the analysis can be expanded to include a whole company or several companies that form a value network. The results could help to explain the formation of network relationships and facilitate cooperation between companies. An example of such analysis is the inclusion of telecommunications equipment manufacturers in the value network.

Telecom Finland will use the framework in its service development projects in the future. More empirical data about customer preferences and attributes will be gathered and the effect of service features on the value of attributes will be analysed thoroughly. The methods and results will be utilised in service development pilot projects. The object of pilot projects is to develop succesful differentiated service concepts based on the technological know-how of Telecom Finland.

\section{ACKNOWLEDGEMENTS}

The authors express their sincere appreciation for helpful support they obtained from colleagues, especially from Mr. Sakari Luukkainen, Mr. Kari Koivisto, Dr. Arto Lahti, Dr. Liisa Uusitalo, Mr. Janne Yli-Äyhö, and Mr. Olli Ranta.

\section{REFERENCES}

1. Akao: Quality Function Deployment: Integrating Customer Requirements into Product Design, Productivity Press, Cambridge, Massachusetts, 1990.

2. Bunn: Applied decision analysis, McGraw-Hill, New York, 1984.

3. Gerpott, Schefczuck, and Pospischil: "International efficiency comparisons of Deutsche Telekom“, Communications \& Strategies, no. 10, 2nd quarter 1993. 
4. Glahe and Lee: Microeconomics, theory and applications, Harcourt Brace Jovanovich, New York, 1981.

5. Green and Srinisavan: Conjoint analysis in consumer research: issues and outlook, Journal of Consumer Research, vol. 5, September 1978.

6. Infosino, Parker, and Unger: "Market analysis and product design for telecommunications equipment and services“, AT\&T Technical Journal, March\&April 1991.

7. Kotler: Marketing management: analysis, planning, implementation, and ontrol, Prentice-Hall, Englewood Cliffs, New Jersey, 1988.

8. Lahti and Martikainen: Value creation in networks, Helsinki School of Economics series, 1994.

9. Peter and Olson: Consumer behavior and marketing strategy, Irwin, Homewood, IL, 1990.

10. Porter: Competitive advantage, The Free Press, New York, 1985.

11. Wilkie: Consumer behavior, John Wiley, New York, NY, 1990.

12. Von Winterfeldt and Edwards: Decision analysis and behavioral research, Cambridge University Press, Cambridge, 1986. 